\title{
GARGOYLISM WITH CARDIOVASCULAR INVOLVEMENT IN TWO BROTHERS
}

\author{
BY \\ R. W. EMANUEL \\ From the Department of Cardiology, Middlesex Hospital \\ Received June 20, 1954
}

The term "Gargoyle" was introduced by Ellis, Sheldon, and Capon in 1936. The condition was first recognized by Thomson in 1900, but his original cases were not reported until later (Henderson and Ellis, 1940). Although about 200 cases have been reported, there are few detailed studies of the cardiovascular system. Necropsy material is rare, and has been reviewed by Strauss (1948) and Lindsay (1950). Since then other necropsies have been reported by Jervis (1950), Magee (1950), Henderson et al. (1952), Millman et al. (1952), Schwarz (1952), and Smith et al. (1952), making a total of 32 in all.

The following observations were made on two brothers, both with gargoylism, who were studied during life and found to have cardiovascular involvement. One died and the post-mortem findings are reported.

\section{History and General Characteristics of the Patients}

The brothers are the only gargoyles in an otherwise normal family. There are three sisters aged 24,14 , and 10 years.

In both, the abnormalities were noted at birth. The elder (R.S.) is 26 years old, and although he has recently had congestive failure with systemic œdema and ascites, he has responded well to digitalis and mercurial diuretics. The younger (D.S.) died at the age of 20 from congestive cardiac failure.

Many of the characteristics can be seen in Fig. 1. R.S. is $4 \mathrm{ft} .8$ in. tall and D.S. was $4 \mathrm{ft} .2 \mathrm{in}$. Both patients were congenitally deaf but had learned to lip read moderately well. They spoke in a deep gutteral voice but formed their words so badly that they were hardly intelligible.

Their heads were large and their features coarse, with prominent superciliary ridges and heavy eyebrows. The lips were thick and the nose broad with a depressed bridge. Both had large tongues and widely spaced peg-shaped teeth. The ears were large and fleshy and placed far down on the skull. The hair was abundant and coarse and each showed abnormally hairy trunk and limbs. They had short necks and in one (R.S.) the thyroid was enlarged and firm, but there were no signs of hyperthyroidism. They had barrel-shaped chests with expansion of less than an inch. In both the abdomen was protuberant with a large umbilical hernia. The liver was enlarged to three finger breadths below the costal margin, but the spleen was only felt in the elder brother (R.S.).

They had many skeletal abnormalities. Their hands were wide with clawed fingers which showed flexion deformities of the interphalangeal joints; flexion deformaties were also present in all joints of the upper limbs. Both patients had bilateral pes cavus with clawed toes. The spines in each lacked the normal cervical and thoracic curves but did not show the angular kyphosis commonly found in this condition.

Unlike the majority of cases the mental condition in each was considered normal when allowance had been made that both patients were congenitally deaf. There were no corneal opacities. 


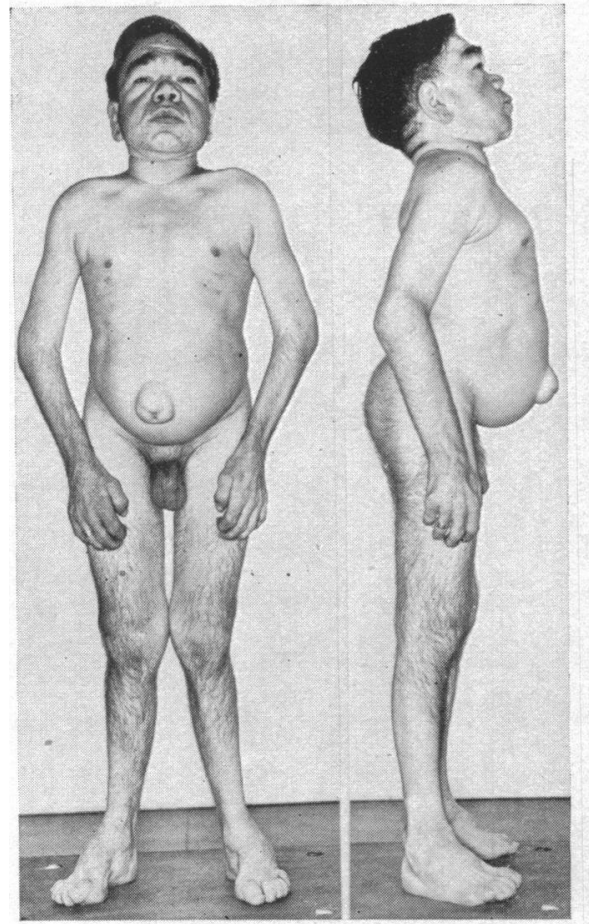

A

B

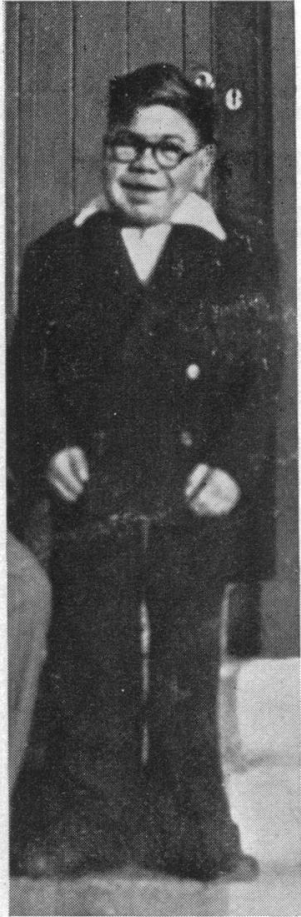

C

Fig. 1.-(A) and (B) R.S., aged 26. Height $4 \mathrm{ft} .8$ in. Coarse features, protuberant abdomen with umbilical hernia, clawed hands with flexion deformities of limbs and fingers, bilateral pes cavus, and hirsuites. (C) D. S., aged 20. Height $4 \mathrm{ft} .2$ in.

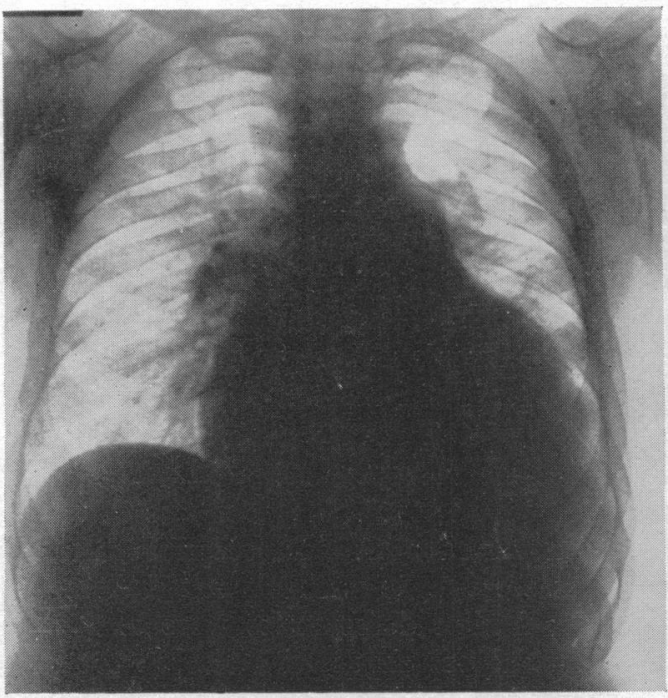

A

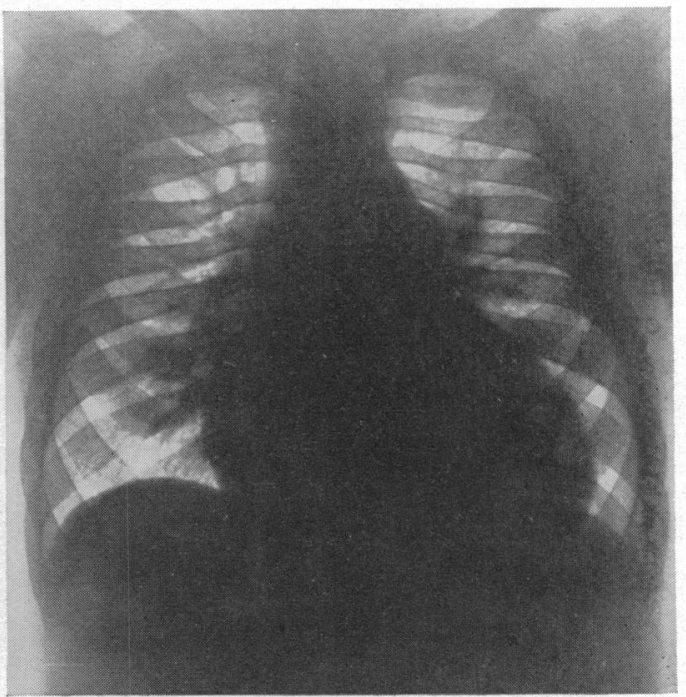

B

FIG. 2.-(A) Chest X-ray (R.S.). Enlarged heart (c.t.r. 66\%). Prominent pulmonary artery. (B) Chest X-ray (D.S.). Enlarged heart (c.t.r. 65\%). Prominent pulmonary artery. The spatulate appearance of the ribs is more obvious than in Fig. 2A. 
Cardiovascular System. At various times both patients showed signs of congestive failure. The pulse was regular and the blood pressure normal (R.S., 120/80: D.S., 130/85 mm. Hg).

The heart was considerably enlarged in both cases; in R.S. the apex beat was localized and thrusting, suggesting left ventricular enlargement, while in D.S. the apex beat was tapping and there was diffuse pulsation over the right ventricle. In both patients the closure of the pulmonary valves was palpable and a Graham Steell murmur was present. In R.S. there was also an apical systolic murmur.

In R.S. it was difficult to explain why the apex beat was left ventricular in character in the presence of signs that were suggestive of pulmonary hypertension; it was thought, however, that the skeletal deformity of the chest might have masked the true character of the apex beat.

These physical signs would indicate that both brothers had cor pulmonale probably due to the chest deformities. The primary effect of gargoylism on the heart was not apparent on clinical examination.

$X$-rays of the heart were similar in the two cases and showed generalized cardiac enlargement with an enlarged pulmonary artery and small aorta (Fig. 2).

The electrocardiogram in both cases was consistent with right ventricular enlargement and clockwise rotation of the heart. In R.S. the first cardiogram had deep $T$ wave inversion in standard lead III and V1 to V4 with a prominent $R$ wave in V1 and deep S waves extending from V2 to V5 (Fig. 3A). Two hours later, it had changed to a complete right bundle branch block which reverted to the previous pattern by the following day. The cardiogram of D.S. showed right axis deviation in a vertical heart, with inversion of the T wave in standard lead III and V1 to V2 with biphasic $\mathrm{T}$ waves in V3 to V4. In V1 there was an $\mathrm{rSr}$ complex with deep S waves extending from V2 to V5 (Fig. 3B).

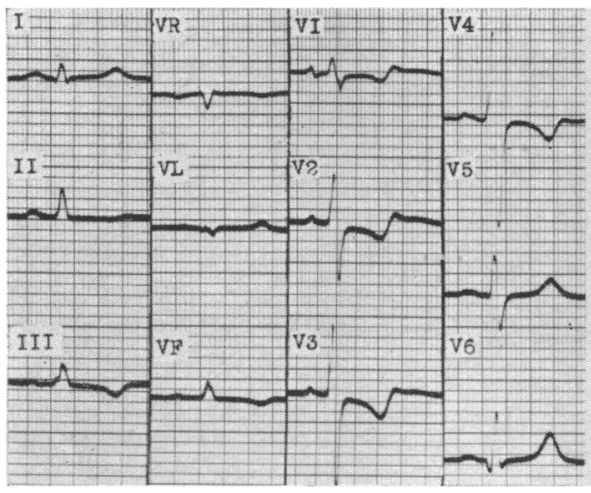

A

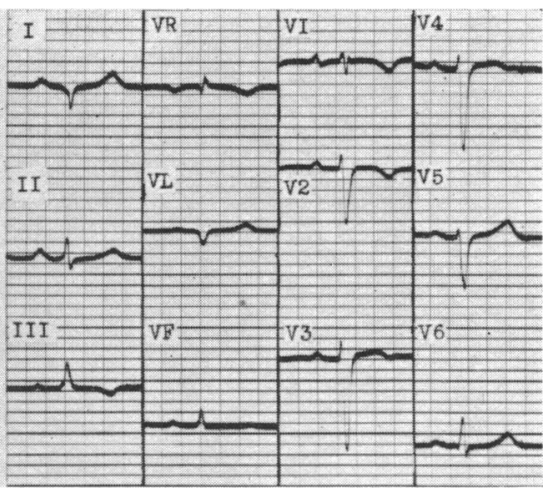

B

Fig. 3.-Electrocardiograms showing right ventricular enlargement with clockwise rotation. (A) From R.S. T inversion lead III and V1-V4. Prominent R in V1 and deep $\mathrm{S}$ in V2-V5. (B) (D.S.) Right ventricular enlargement with clockwise rotation. Right axis deviation with $\mathrm{T}$ inversion in lead III and V1-V2. Biphasic $\mathrm{T}$ in V3-V4. rSr complex in V1 and deep S waves in V2-V5.

$X$-rays of the Skeleton. The skull in both was large with a thick vault and the antra were small. In R.S., the frontal sinuses were normal and the pituitary fossa enlarged, while in D.S., the frontal sinuses were under-developed and the pituitary fossa normal.

The hands in both showed delayed ossification. There was deformity of the epiphysis, particularly the heads of the metacarpals. The shafts of the metacarpals and phalanges were clawed.

The spine in both cases lacked the kyphosis usually seen in this condition. In R.S., there were defects in the upper and lower margins of the vertebræ, most marked in the lumbar region and no beaking of the vertebral bodies. In D.S., the bodies of the dorsal vertebræ were infantile in shape, 
the lumbar vertebræ were deformed with slight beaking at the lower margins, there was some backward displacement of the first lumber vertebræ, and all the lumbar disc spaces were narrowed.

The ribs in both cases were broad and spatulate. The long bones showed malformation of the epiphyses, the shafts were slender with increased curvature.

\section{Post-Mortem Findings IN D.S. AGED 20 Years}

The external appearances were as already described, but in addition there was ascites and œdema of the legs and lower part of the trunk.

The heart weighed $397 \mathrm{~g}$. The pericardium contained an abnormally large quantity of fluid, but was otherwise normal. The epicardium showed some patchy thickening over the ventricular surface. The right atrium and ventricle were dilated and thickened while the left atrium and ventricle appeared normal.

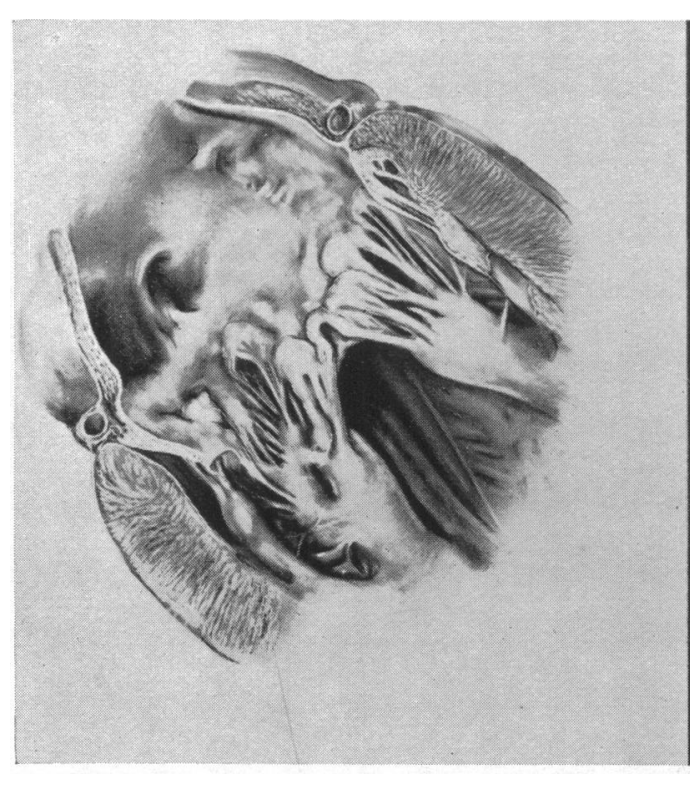

A

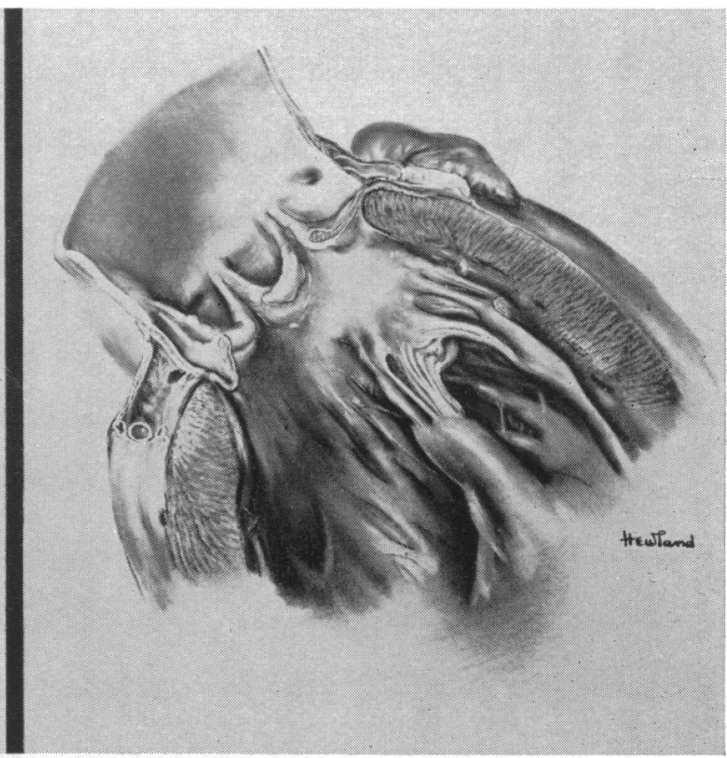

B

FIG. 4.-(A) Dissection of heart (D.S.), showing mitral valve with nodular thickening of the cusps and shortened chordae tendinex. (B) Dissection of heart (D.S.), showing aortic valve with rigid thickened cusps.

The valves were all abnormal. The mitral valve had gelatinous nodules up to 4-5 $\mathrm{mm}$. in diameter on its atrial surface; these nodules were hollow and protruded upwards from the free margin of the cusps. The commissures were not adherent (Fig. 4A). The aortic cusps were thickened with a rolled edge; in places the thickening amounted to $2 \mathrm{~mm}$. (Fig. 4B). The pulmonary cusps were similar to the aortic though involved to a lesser degree. The tricuspid valve was like the mitral, but the gelatinous nodules were smaller and less numerous. There was patchy thickening of the endocardium over the ventricular surfaces and the chordæ tendineæ were short and thickened (Fig. 4A).

The coronary arteries were abnormal and stood out through the epicardium as thickened white cords. This was due to a nodular thickening which was most marked in the left anterior descending branch. The ostium of the right coronary was double, but there was no stenosis.

The pulmonary artery was greatly enlarged, the wall being thicker than that of the aorta, which was normal.

The lungs, liver, brain and other organs showed congestive changes. 
Histological Report on the Heart.-In the myocardium of the atria and ventricles there was increased interstitial fibrosis maximal around the branches of the coronary arteries. This fibrosis was acellular and unaccompanied by inflammatory foci. The myocardial fibres were hypertrophied with enlargement of the nuclei. There were small patches of vacuolated connective tissue cells.

Valve cusps from the mitral, tricuspid, aortic, and pulmonary valves were thickened due to fibrosis with hyaline degeneration. Surrounding this there was cellular fibrous tissue containing vacuolated connective tissue cells. These changes were maximal in the sub-endocardial areas. The endocardium was normal except for a few small thickened areas which showed hyaline fibrosis containing vesicular cells.

The coronary arteries showed concentric thickening of the walls due to a subintimal fibrosis causing a narrowing of the lumen. The fibrous tissue contained vacuolated connective tissue cells which interrupted the internal elastic lamina and extended into the media. The intima was intact.

In the pulmonary artery there was subintimal fibrosis and in the media prominence of the elastic fibres between which there were a few vacuolated connective tissue cells. The vasa vasorum and adventitia were normal. Similar but less marked changes were found in the aorta.

\section{Discussion AND CONCLUSION}

Many gargoyles die in childhood, but the two patients described had reached the third decade. R.S. is 26 years old which probably makes him the seventh oldest gargoyle on record. Two cases aged 37 years have been reported (Hooper, 1952; Schwarz, 1952).

From a study of the 32 post-mortem reports available, cardiovascular abnormalities were found in 22; in 4 the cardiovascular system was normal and in the remaining 6 no mention was made of the heart. If we exclude these cases, cardiac involvement of a varying degree occurred in 85 per cent of gargoyles. Cardiac enlargement $(73 \%)$ and deformity of the valves $(77 \%)$ were the main features in the 22 abnormal hearts. The mitral valve was affected in 15 , the aortic in 9, the tricuspid in 7, and the pulmonary in 2: in only 2 cases, were all the valves involved. Other cardiovascular abnormalities recorded were as follows: endocardial thickening (7 cases), coronary artery involvement ( 5 cases), and epicardial thickening ( 3 cases).

In our case (D.S.) extreme cardiac involvement was shown by changes in the heart size, all four valves, epicardium, endocardium, and coronary and pulmonary arteries. Only two other such cases have been reported (Strauss, 1948; Lindsay et al., 1948, Case 7).

One of the interesting features of these two brothers was the similarity of their physical signs, particularly in the cardiovascular systems. Both had gross cardiac enlargement with pulmonary incompetence. The X-rays and cardiograms were similar. We may therefore infer that the elder also has extensive cardiac involvement, probably similar to that found in his brother at autopsy.

Since submitting this paper the pulmonary artery pressure has been measured in R.S. by cardiac catheterization and found to be $88 / 50 \mathrm{~mm}$. $\mathrm{Hg}$ with a mean of $61 \mathrm{~mm}$. $\mathrm{Hg}$.

\section{SUMMARY}

Two brothers with gargoylism and cardiac abnormalities are reported. The similarity of their physical signs is noted.

Post-mortem findings with special reference to the heart are reported in the case of the younger brother.

I am indebted to Dr. Evan Bedford for his permission to publish these cases, and also to Dr. H. Sterndale, Pathologist to the Thanet Group of Hospitals who performed the necropsy and was kind enough to send me the heart for examination. I wish to thank Dr. A. D. Thompson of the Bland Sutton Institute of Pathology, Middlesex Hospital, for the histology and Dr. J. N. Pattinson of the X-ray Department, Middlesex Hospital for the X-rays. I should like to express my appreciation of the co-operation received from Drs. W. B. and J. A. Loveless of Ramsgate under whose care these patients have been for many years.

\section{REFERENCES}

Ellis, R. W. B., Sheldon, W., and Capon, N. B. (1936). Quart. J. Med., 29 (n.s. 5), 119. Henderson, J. L., and Ellis, R. W. B. (1940). Arch. Dis. Childh., 15, 201.

-, MacGregor, A. R., Thannhauser, S. J., Holden, R. (1952). Arch. Dis. Childh., 27, 230.

Hooper, J. M. D. (1952). Guy's Hosp. Rep., 101, 222.

Jervis, G. A. (1950). Arch. Neurol. Psychiat., Chicago, 63, 681.

$2 \mathrm{E}$ 
Lindsay, S. (1950). Brit. Heart J., 12, 17.

—, Reilly, W. A., Gotham, T. J., and Skahen, R. (1948). Amer. J. Dis. Childh., 76, 239.

Magee, K. R. (1950). Arch. Neurol. Psychiat., Chicago, 63, 282.

Millman, C. G., and Whittick, J. W. (1952). J. Neurol. Neurosurg. Psychiat., 15, 253.

Schwarz, H., and Gagne, R. (1952). Canad. med. Ass. J., 66, 375.

Smith, E. B., Hempelmann, T. C., Moore, S., and Barr, D. P. (1952). Ann. intern. Med., 36, 652.

Strauss, L. (1948). Amer. J. Path., 24, 855.

Thomson, J. (1900). See Henderson, J. L., and Ellis, R. W. B. (1940). 